\section{National clinical guidelines for the extraction of first permanent molars in children}

\author{
M. T. Cobourne, ${ }^{* 1}$ A. Williams ${ }^{2}$ and M. Harrison ${ }^{3}$
}

IN BRIEF
- Describes the updated national clinical
guidelines for the extraction of first
permanent molars in children.
- Presents the most up-to-date evidence to
support clinical decision-making.
- Informs GDPs who play an important role
in managing the developing dentition.
- Educates dentists on the issues that need
to be considered when managing first
permanent molars of poor prognosis in
children.

\begin{abstract}
This article summarises recently updated guidelines produced by the Clinical Governance Directorate of the British Orthodontic Society through the Clinical Standards Committee of the Faculty of Dental Surgery, Royal College of Surgeons of England (FDSRCS) on the extraction of first permanent molars in children. The first permanent molar is susceptible to chronological enamel defects, molar-incisor hypomineralisation and caries, which may necessitate enforced extraction in the developing dentition. In the right circumstances, the extraction of these teeth can be followed by successful eruption of the second permanent molar and ultimately, third molar eruption to complete the molar dentition. For this reason, elective extraction of first permanent molars with a questionable long-term prognosis should be considered when planning enforced extractions. However, a number of factors can influence the decision-making process, including the necessity for a general anaesthetic to allow extraction, potential cooperation with restorative or orthodontic treatment and likely future preventative practice within the family. Moreover, the presence of any underlying malocclusion also needs to be evaluated within the context of extraction planning. The current available evidence has been evaluated and awarded a grade based upon those recommended by the Scottish Intercollegiate Guidelines Network.
\end{abstract}

\section{INTRODUCTION}

It is important for practising dental surgeons to access and use appropriate clinical guidelines. The Faculty of Dental Surgery at the Royal College of Surgeons of England (FDSRCS Eng) develops and maintains a wide range of clinical guidelines through its Clinical Standards Committee. These either represent work of the committee itself or the endorsement of work by other bodies, such as professional societies. This paper represents updated guidance produced in 2014 by the Clinical Governance Directorate of the British Orthodontic Society through the FDSRCS Eng on the extraction of first permanent molars in children. ${ }^{1}$

Children can present with a developing dentition affected by one or more first permanent molars of poor prognosis, which may necessitate their enforced extraction. In the right circumstances, first permanent molar extraction can be followed by successful eruption of the second permanent

Professor of Orthodontics, King's College London and Honorary Consultant in Orthodontics, Guy's and St Thomas' NHS Foundation Trust; ${ }^{2}$ Specialist in Orthodontics, ${ }^{3}$ Consultant in Paediatric Dentistry, Guy's and St Thomas' NHS Foundation Trust

${ }^{*}$ Correspondence to: Professor Martyn T. Cobourne Email: martyn.cobourne@kcl.ac.uk

\section{Refereed Paper}

Accepted 7 August 2014

DOI: 10.1038/sj.bdj.2014.1053

${ }^{\circ}$ British Dental Journal 2014; 217: 643-648
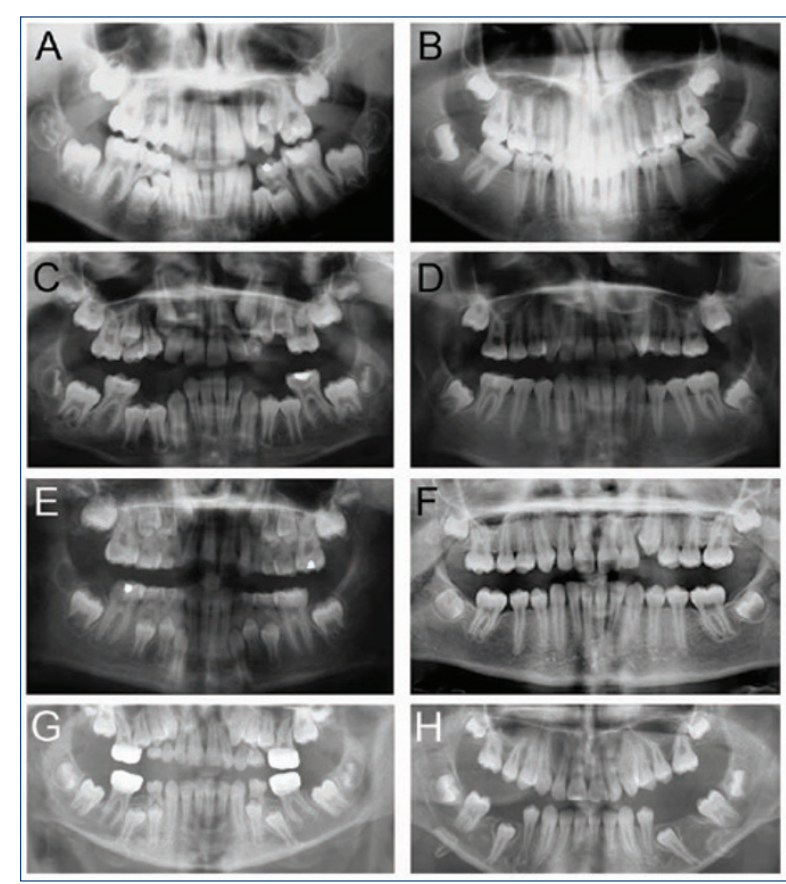

Fig. 1 Panoramic radiographs showing occlusal outcome following the enforced extraction of first permanent molars. (A, B) Loss of the lower first permanent molars resulting in successful eruption of the second permanent molars; (C, D, E, F) extraction of all four first permanent molars resulting in eruption of the second permanent molars, with a good axial inclination and no spacing; $(G, H)$ a less satisfactory result following the loss of all four first permanent molars, with significant spacing present in the lower arch. In all these examples, the third permanent molars are present. Left panels are before first permanent molar extraction and right panels are following second permanent molar eruption molar to provide a suitable replacement, and ultimately third molar eruption to complete the molar dentition, although this is not guaranteed (Fig. 1). For this reason, elective extraction of first permanent molars with a questionable long-term prognosis should also be considered when planning enforced extraction of these teeth. These treatmentplanning decisions should ideally be made following input from both the general or paediatric dentist and the orthodontist, although this may not always be possible.

These guidelines offer advice on the extraction of first permanent molars in the child. However, it is important to remember that in addition to the presenting clinical features, a number of additional factors may influence decision-making. These include a child's social background, the necessity for general anaesthetic to allow extraction 
of these teeth, the likelihood of the child cooperating with restorative or orthodontic treatment, prevention and oral hygiene practice within the family, as well as any local difficulties in accessing NHS restorative or orthodontic treatment. The best available evidence for each treatment option (Table 1) has been assigned an overall grade in accordance with the Scottish Intercollegiate Guidelines Network (SIGN) grading scheme (Table 2). ${ }^{2}$

\section{DEVELOPMENT OF THE FIRST PERMANENT MOLAR}

The first permanent molar is derived from the primary dental lamina and morphological evidence of its formation is usually present in the human embryo by week 17 of gestation. ${ }^{3}$ Hard tissue formation has generally initiated in these teeth by birth and coronal development is complete by the third year of life. Eruption of the first permanent molars occurs around the age of 6-7 years and root formation is complete by the age of 9-10 years. ${ }^{4,5}$

The relative timing of crown formation makes the first permanent molar susceptible to chronological enamel defects, which can lead to hypomineralisation and/or hypoplasia $;{ }^{6}$ while combined first permanent molar-incisor hypomineralisation (MIH) is a recognised condition of unknown aetiology ${ }^{7}$ with a prevalence in the literature ranging from $10-30 \%$ (Fig. 2). ${ }^{8,9} \mathrm{MIH}$ is a frequent compromising factor for first permanent molars. The extent of the enamel defects and degree of hypomineralisation often vary between quadrants, with the prognosis for any particular molar usually evaluated by the degree of post-eruptive breakdown within the defect or the extent to which this is anticipated to occur. These teeth can present with large carious lesions, often with only minimal evidence of a pre-existing enamel defect. Intra-coronal restorations generally fail in severely hypomineralised molars, so maintaining them throughout adulthood requires full-coronal restorations. Given the periodic need for crown replacement and the fact that defective teeth are often present in multiple quadrants, keeping MIH-affected molars can condemn the patient to the morbidity and expense of dental treatment for these teeth throughout their lifetime. Where molars affected by severe MIH are to be maintained until planned extraction before orthodontic treatment, pre-formed metal crowns provide the most robust provisional restoration. These can be placed with minimal or even no tooth preparation.

The timing of first molar eruption also makes these teeth vulnerable to dental caries. Although caries experience has continually fallen in the permanent dentition of UK children over the last 30 years, the most recent

\section{Table 1 Levels of clinical evidence}

\begin{tabular}{|c|c|}
\hline $1++$ & High quality meta-analyses, systematic reviews of RCTs, or RCTs with a very low risk of bias \\
\hline $1+$ & Well-conducted meta-analyses, systematic reviews, or RCTs with a low risk of bias \\
\hline $1-$ & Meta-analyses, systematic reviews, or RCTs with a high risk of bias \\
\hline $2++$ & $\begin{array}{l}\text { High quality systematic reviews of case control or cohort or studies. High quality case control or } \\
\text { cohort studies with a very low risk of confounding or bias and a high probability that the relation- } \\
\text { ship is causal }\end{array}$ \\
\hline $2+$ & $\begin{array}{l}\text { Well-conducted case control or cohort studies with a low risk of confounding or bias and a moder- } \\
\text { ate probability that the relationship is causal }\end{array}$ \\
\hline 2- & $\begin{array}{l}\text { Case control or cohort studies with a high risk of confounding or bias and a significant risk that the } \\
\text { relationship is not causal }\end{array}$ \\
\hline 3 & Non-analytic studies, for example, case reports, case series \\
\hline 4 & Expert opinion \\
\hline
\end{tabular}

\section{Table 2 SIGN grades of evidence recommendations}

\begin{tabular}{l|l} 
A & $\begin{array}{l}\text { At least one meta-analysis, systematic review, or RCT rated as } 1++, \text { and directly applicable to the } \\
\text { target population; or } \\
\text { A body of evidence consisting principally of studies rated as } 1+\text {, directly applicable to the target } \\
\text { population, and demonstrating overall consistency of results }\end{array}$ \\
\hline B & $\begin{array}{l}\text { A body of evidence including studies rated as } 2++ \text {, directly applicable to the target population, and } \\
\text { demonstrating overall consistency of results; or } \\
\text { Extrapolated evidence from studies rated as } 1++ \text { or } 1+\end{array}$ \\
\hline C & $\begin{array}{l}\text { A body of evidence including studies rated as } 2+\text {, directly applicable to the target population and } \\
\text { demonstrating overall consistency of results; or } \\
\text { Extrapolated evidence from studies rated as } 2++\end{array}$ \\
\hline D & $\begin{array}{l}\text { Evidence level } 3 \text { or } 4 ; \text { or } \\
\text { Extrapolated evidence from studies rated as } 2+\end{array}$
\end{tabular}
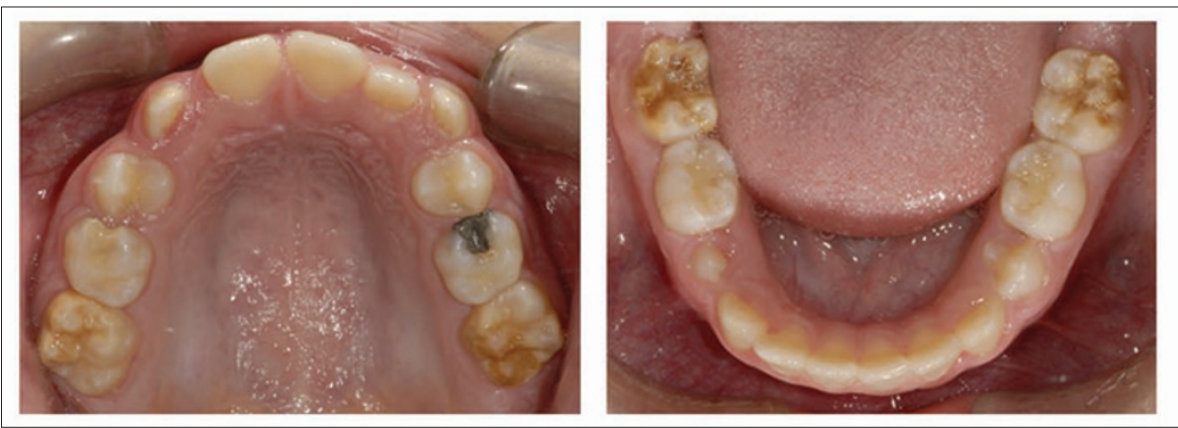

Fig. 2 Molar incisor hypomineralisation (MIH) in the mixed dentition. The first permanent molars have significant occlusal breakdown

data have demonstrated that around one is prescribed, a radiographic screen should be third of UK 15-year-olds still have experience of caries into dentine in at least one of their permanent teeth. ${ }^{10}$ Currently, the majority of first permanent molars are extracted because of dental caries. ${ }^{11}$

\section{FIRST PERMANENT MOLARS OF POOR PROGNOSIS}

A child presenting with a developing dentition affected by one or more first permanent molars of poor prognosis may require their enforced extraction or consideration toward their elective extraction in the form of balancing or compensating extractions. At this stage, balancing or compensating extractions of sound first molars should also be considered as part of the treatment planning process.

Before the elective extraction of any teeth is prescribed, a radiographic screen should be
carried out to check for the presence, position and normal formation of the developing permanent dentition. Any other primary teeth of questionable prognosis should also be considered as candidates for balancing or compensating extraction, particularly if general anaesthesia is required. It can be more difficult to justify these extractions if local anaesthesia is used for the enforced extraction of a single symptomatic tooth and cooperation for further extractions may be poor.

\section{BALANCING AND COMPENSATING EXTRACTIONS (SIGN GRADE C)}

The practice of compensating and balancing the extraction of first permanent molars aims to preserve occlusal relationships and arch symmetry within the developing dentition. 

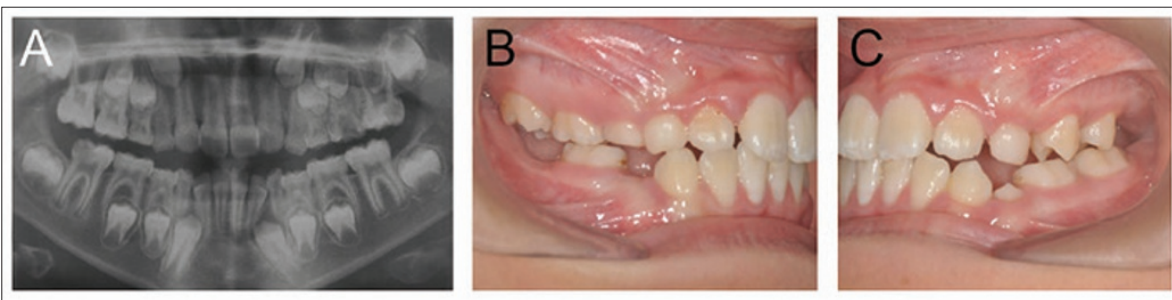

Fig. 3 The enforced extraction of thr 26 and 46 in this 9-year-old girl with a developing Class I malocclusion has not led to over-eruption of the unopposed 16 on review one year later. (A) Panoramic radiograph before extractions; $(B, C)$ right and left buccal occlusion one year later

In this context, a compensating extraction is the removal of a first permanent molar from the opposing quadrant, while a balancing extraction refers to the removal of a first permanent molar from the opposite side of the same dental arch. A number of factors can influence whether a first permanent molar is recommended for either a balancing or compensating extraction:

- Which of the first permanent molar/s requires enforced extraction

- The overall condition and long-term prognosis of the remaining first permanent molar/s

- The teeth present and developmental status of the dentition (including third molars)

- The underlying malocclusion.

As a general rule, the compensating extraction of an upper first permanent molar has been recommended when extraction of the lower first permanent molar is required. ${ }^{12}$ This is to avoid over-eruption of an unopposed upper first permanent molar, which can prevent desirable mesial movement associated with the erupting lower second permanent molar and potentially cause other occlusal interferences. There is very little formal data to either verify or refute these claims. However, the risk of upper first permanent molar over-eruption as a consequence of lower first permanent molar extraction would seem to be relatively small (Fig. 3) $)^{13,14}$ although this evidence is based on retrospective cohort studies, often with very small sub-samples. ${ }^{12-14}$ A randomised controlled trial has been registered, which aims to provide more reliable evidence as to whether compensating extraction of upper first permanent molars should be carried out in conjunction with the enforced extraction of lower first permanent molars. ${ }^{15}$

When the enforced extraction of a lower first permanent molar is required, consideration should be given toward compensating extraction of the upper first permanent molar if this tooth is likely to remain unopposed for a significant length of time (Fig. 4). Routine compensating extraction of a lower first permanent molar in conjunction with enforced extraction of the upper first permanent molar is not recommended, particularly if this would mean a general anaesthetic and also if there is no evidence of a developing third permanent molar.

The balancing extraction of sound first to preserve arch symmetry. ${ }^{16,17}$ Retrospective with the development of both skeletal and dental arch asymmetries ${ }^{18,19}$ evidence from similar study designs suggests that the dental centreline in either dental arch is unlikely to be affected. ${ }^{13,14}$ Currently, it is difficult to justify the balancing extraction of a sound first permanent molar alone to preserve a dental centreline.

\section{TREATMENT PLANNING GOALS}

Ideally, first permanent molar extractions should be followed by successful eruption of the second molars to replace them and ultimately, the third molars. However, achieving this can be complicated by a number of factors:

- Timing of first permanent molar extraction can influence the subsequent eruptive position of the second molar, particularly in the lower arch

- Third molar development cannot always be confirmed at the time extraction decisions have to be made (Fig. 5).

In addition, consideration also needs to be given to the consequences of first molar extraction for the developing occlusion, particularly in the presence of an underlying malocclusion. In many cases, at least one first permanent molar may require enforced extraction because of its poor condition and unfavourable long-term prognosis. At this stage, a decision should also be made regarding the need for elective extraction of any other teeth. This decision will be influenced primarily by their condition and the underlying occlusion. Before any extraction decisions are made, good quality radiographs are required to show the presence, condition and developmental stage of all teeth in the dentition. If any teeth in the permanent dentition are missing or in a poor eruptive position, this can significantly permanent molars has been recommended cohort studies have suggested that unilateral first molar extraction can be associated

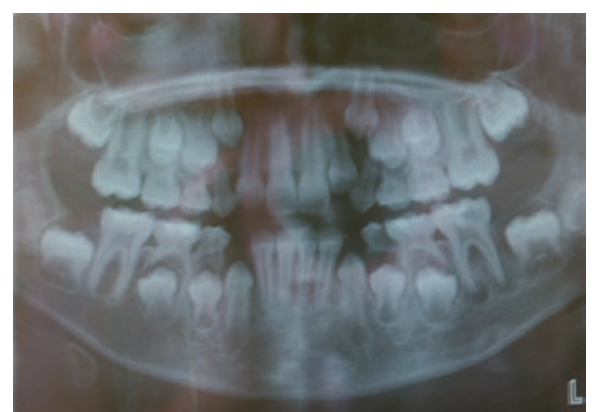

Fig. 4 Panoramic radiograph of an 8-yearold girl with a Class I malocclusion who requires enforced extraction of a carious and symptomatic 36 . Although there is evidence of lower third permanent molar development, the upper third permanent molars are not present. There is currently insufficient evidence to definitively recommend the compensating extraction of the 26 in this case
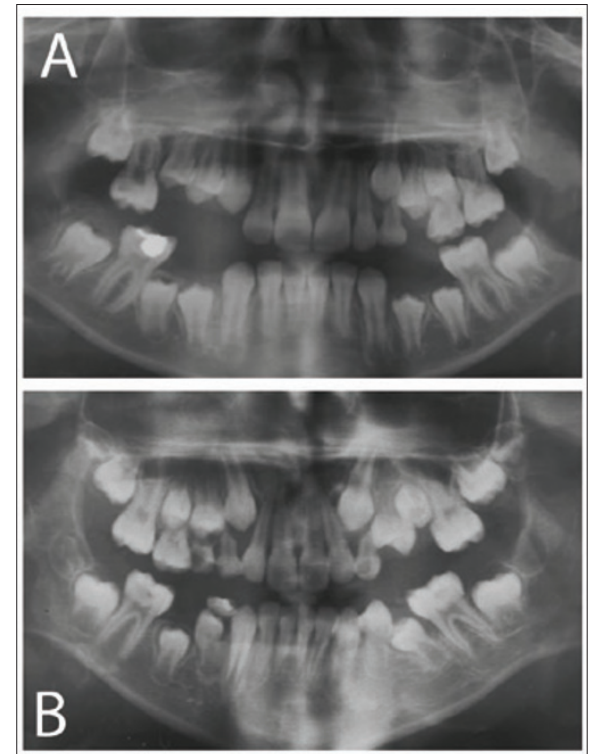

Fig. 5 Chronological variation in development of the molar dentition. Panoramic radiographs of two developing dentitions complicated by the presence of first permanent molars with a poor long-term prognosis. (A) This child is 11 years old but there is no evidence of third permanent molar development; (B) this child is only $\mathbf{9}$ years old, but there is evidence of early third permanent molar development in three quadrants $(18,28,48)$

affect the decision-making process. Ideally, an orthodontic opinion should be obtained, preferably from the orthodontist responsible for future treatment, whenever this is practically possible.

- In the absence of a definitive opinion and if the use of local anaesthetic is practical, enforced extraction should be carried out and advice sought regarding further elective extractions

- If a general anaesthetic is the only option, advice on elective extractions should be obtained beforehand if at all possible, to prevent the risk of multiple anaesthetics. 


\section{IDEAL TIMING OF FIRST \\ PERMANENT MOLAR EXTRACTION (SIGN GRADE C)}

In the upper arch, an unerupted second permanent molar will generally achieve a good occlusal position following extraction of the first permanent molar; however, in the lower arch occlusal outcome can be more variable and less predictable. ${ }^{20-24}$

The timing of first permanent molar extraction in the lower arch is more important for successful eruption of the second permanent molar. The most favourable chronological age range is $8-10$ years, after eruption of the lateral incisors but before eruption of the second permanent molar and/or second premolar. ${ }^{23,24}$

Analysis of second permanent molar development as a predictor for successful eruption suggests that radiographic evidence of calcification within the root bifurcation produces the best occlusal position. However, the response of the second permanent molar is variable and acceptable positions are also possible in association with extraction at earlier or later stages of second molar development. ${ }^{21}$ Favourable mesial movement of mandibular second permanent molars seems to be most predictable if radiographs show they are still within bone at the time of extraction of the first permanent molar.

If the first permanent molar is extracted before the age of eight years, there is often no radiographic evidence of third molar development. In addition, in the lower arch:

- The second premolar can drift

distally into the extraction space,

tip and rotate ${ }^{24,25}$

- The labial segments can retrocline

with an accompanying increase in the overbite. ${ }^{24-27}$

If the first permanent molar is extracted during the later stages of second molar eruption, there is more risk that the second molar may tip mesially and rotate, producing spacing and poor occlusal contacts. ${ }^{22-24,28}$ In addition, the erupted second premolar can migrate distally. There is some retrospective evidence that first permanent molar extraction can accelerate the development and eruption of the third molar in both the upper and lower jaws. ${ }^{29-32}$

Extraction of a first permanent molar is rarely the extraction of choice. However, favourable spontaneous development of the dentition and space closure can be expected in many cases. ${ }^{13,14,21}$ It is also possible to achieve good results following the removal of these teeth using fixed appliances, although treatment times tend to be increased and appropriate mechanics need to be used. ${ }^{33,34}$ It is not advisable to extract a healthy premolar for
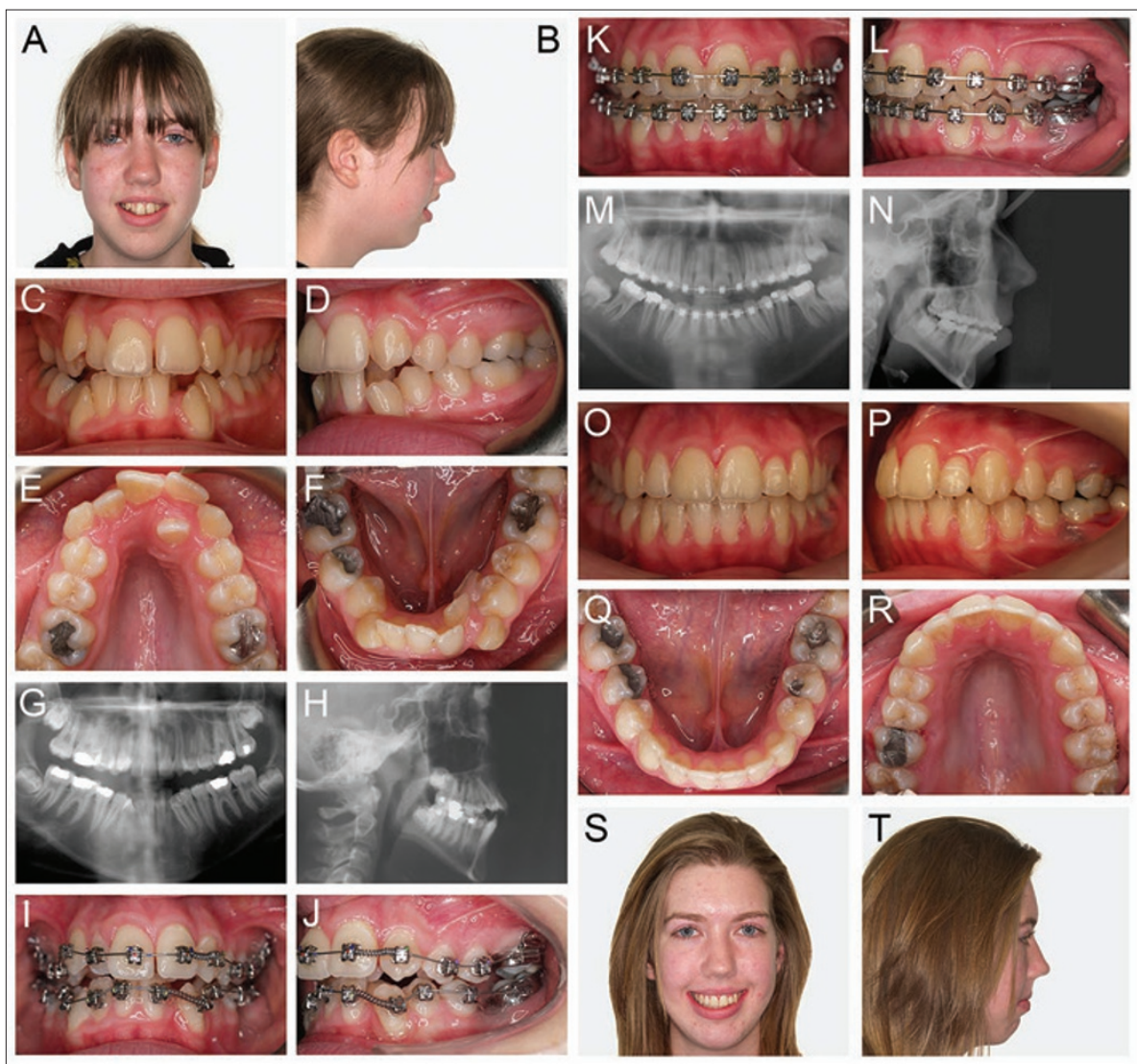

Fig. 6 Treatment of a Class II division 1 case with severe crowding following the extraction of all four heavily restored first permanent molars. Pre-adjusted fixed appliances were used in conjunction with high-pull headgear to align the teeth, reduce the increased overjet and coordinate the dental arches. (A-F) Pre-treatment clinical records; (G, H) pre-treatment radiographs; $(I, J)$ fixed appliances during initial alignment; $(K, L)$ fixed appliances during final space closure; $(M, N)$ near end-of-treatment radiographs; $(O-T)$ post-treatment clinical records. This case also illustrates some of the difficulties associated with managing patients that have an increased susceptibility to caries. Despite excellent cooperation with the orthodontic appliances, the 35 and $\mathbf{3 7}$ became carious and required restoration. In addition, white spot lesions were evident on the upper lateral incisors following removal of the fixed appliances

orthodontic purposes if the first permanent molar in the same quadrant is heavily restored.

\section{GUIDELINES FOR ELECTIVE FIRST MOLAR EXTRACTION (SIGN GRADE C)}

A number of general guidelines on treatment planning first permanent molar extraction cases within the context of different malocclusions are available. ${ }^{16,34-36}$ As a general rule, if in doubt, get the patient out of pain, try and maintain the teeth and refer for a specialist orthodontic opinion. In recent years, fixed anchorage devices have become more routinely available in orthodontics and these provide further options in the management of first permanent molar extraction cases, particularly in terms of anchorage reinforcement and space closure.

\section{CLASS I CASES}

\section{Class I cases with minimal crowding}

Aim for extraction at the optimal time for eruption of the second permanent molars into a good position.
- Do not balance unilateral first permanent molar extraction in either the upper or lower jaws with healthy first permanent molars

- If the lower first permanent molar is to be lost, compensating extraction of the upper first molar can be considered if this tooth is likely to be unopposed for a significant length of time

- If the upper first permanent molar is to be lost, do not compensate with extraction of the lower first permanent molar if it is healthy.

\section{Class I cases with moderate crowding}

In the presence of moderate crowding in the buccal segments, extract at the optimal time to allow eruption of second molars into a good occlusal position, which should also provide some relief of crowding.

- If the buccal segment crowding is bilateral, consider balancing extraction of the contralateral first permanent molar to provide suitable relief, particularly if there is any question regarding the long-term 
prognosis for this tooth

- Compensating extraction of upper first permanent molars can be considered to relieve premolar crowding

- In the presence of crowding in the labial segments, little spontaneous relief is provided by first permanent molar extraction

- First permanent molar extractions can be delayed until the second permanent molars have erupted and then the extraction space used for alignment with fixed appliances

- Alternatively, first permanent molars can be extracted at the optimum time and the crowding treated once in the permanent dentition. If premolar extractions are likely to be required at this stage, the third molars should be present.

\section{CLASS II CASES}

The extraction of first permanent molars in Class II cases can be more difficult to plan, particularly with regard to the timing of upper first permanent molar extraction. The main complicating factors often involve the upper arch because of the need for space to correct the incisor relationship.

\section{Class II cases with minimal crowding}

Lower first permanent molar extraction should be carried out at the ideal time for successful eruption of the second permanent molar and control of the second premolar; however, in the upper arch, space will often be required to correct the incisor relationship.

If the upper first permanent molars require immediate extraction, orthodontic treatment may be instituted to correct the incisor relationship. A functional appliance or removable appliance and headgear can be used to correct the buccal segment relationship, followed by fixed appliances if required. Alternatively, after extraction of the upper first permanent molars, the second permanent molars can be allowed to erupt and the incisor relationship corrected once this has taken place. Correction of the malocclusion at this stage can involve any of the methods described above. In addition, if there is radiographic evidence of third molar development, then further space for incisor correction could be created by the loss of two upper premolar teeth.

If the upper first permanent molars can be temporised or restored, then their extraction can be delayed until the second permanent molars have erupted. The resultant extraction space can then be used to correct the malocclusion with fixed appliances (Fig. 6). If the upper first permanent molars are to be left unopposed for any length of time, a simple removable appliance may be required to prevent their over-eruption, while waiting for the second molars to erupt. Alternatively, a functional appliance can be used immediately to correct the incisor relationship before extraction of the first molars and fixed appliances.

If the upper first permanent molars are sound, elective extraction may be indicated if they are at risk of over-erupting; however, the third molars should ideally be present radiographically. The Class II relationship can then be managed as for immediate extraction of upper first molars with a poor prognosis. If there is no sign of upper third molar development, an appliance to prevent the over-eruption of sound upper first permanent molars should be considered and the malocclusion managed following eruption of the second permanent molars.

The maintenance of overbite correction can be very challenging in Class II division 2 cases requiring prolonged space closure following extraction of first permanent molars after second permanent molar eruption. Indeed, there is some retrospective evidence that first permanent molar extraction can be associated with incisor uprighting and an increase in the overbite. ${ }^{24-27}$

\section{Class II case with crowding}

In the presence of crowding, space requirements will be greater. In the lower arch, space will be required for crowding relief, while in the upper arch there will be an increased demand on space available for correction of the incisor relationship.

- If the third molars are present radiographically, lower first permanent molars can be extracted at the optimum time to allow second permanent molar eruption and then premolars extracted at a later stage for the correction of crowding. In these cases, fixed appliances will usually be required

- Alternatively, first permanent molars can be extracted after second permanent molar eruption and the space used directly for the correction of crowding with fixed appliances

- Balancing and compensating extraction of lower first permanent molars are not generally required.

Because space requirements in the upper arch can be significant, upper first permanent molars should be temporised or restored if at all possible and the child referred to a specialist orthodontist. If the upper first permanent molar is unopposed and at risk of over-erupting, if the third molars are present radiographically, then extraction of the upper first permanent molar may be indicated. The patient should be counselled that additional premolar extractions in the upper arch may be required in the future to create sufficient space for crowding relief and incisor correction.

\section{Class III cases}

Class III cases are often difficult to manage and ideally require the opinion of a specialist orthodontist before any first permanent molars are extracted. As a general rule, extraction of maxillary molars should be avoided if at all possible, while balancing and compensating extractions are not recommended in Class III cases. A tendency toward increased residual spacing of the second permanent molar has been described in the lower arch of Class III cases following first permanent molar extraction. ${ }^{21}$

\section{CONCLUSIONS}

Treatment planning for the enforced extraction of first permanent molars can present a complex problem, particularly in the presence of an underlying malocclusion. However, the evidence base for managing first permanent molar extraction is weak, with currently no randomised prospective trials reporting on the outcome of different interventions. When used correctly, modern fixed appliances can achieve excellence following the loss of first permanent molars at a variety of chronological ages, particularly with the advent of fixed anchorage devices.

The authors acknowledge the contributions of Ros McMullen and Iain Mackie in the preparation of the previous RCS guidelines on first permanent molar extraction. We are also grateful to Professor Nigel Pitts for advice on caries experience and first permanent molars.

1. Cobourne M T, Williams A, McMullen R. A guideline for the extraction of first permanent molars in children. Available at: http://www.rcseng.ac.uk/fds/ publications-clinical-guidelines/clinical_guidelines/ documents/A\%20Guideline $\% 20$ for $\% 20$ the $\% 20$ Enforced\%20 Extraction\%20of\%20First $\% 20$ Permanent\%20Molars\%20in\%20Children $\% 20$ rev\%20March\%202009.pdf/view (accessed November 2014)

2. SIGN 50: A Guideline Developer's Handbook. Available at: http://www.sign.ac.uk/guidelines/fulltext/50/index.html (accessed November 2014).

3. Ooe T. Human tooth and dental arch development. Ishiyaku Publishers Inc, 1981.

4. Berkovitz B K B, Holland G R, Moxham B J. Oral anatomy, embryology and histology, 4th ed. Edinburgh: Mosby International Ltd, 2009.

5. Ten Cate A R. Oral anatomy: development, structure and function. St Louis, Missouri: Mosby-Year Book Inc, 2015.

6. Leppaniemi A, Lukinmaa PL, Alaluusua S Nonfluoride hypomineralizations in the permanent first molars and their impact on the treatment need. Caries Res 2001; 35: 36-40.

7. Crombie F, Manton D, Kilpatrick N. Aetiology of molar-incisor hypomineralization: a critical review. Int J Paediatr Dent 2009; 19: 73-83.

8. Jalevik B. Prevalence and diagnosis of molar-incisorhypomineralisation (MIH): a systematic review. Eur Arch Paediatr Dent 2010; 11: 59-64.

9. Kuhnisch J, Heitmuller D, Thiering E et al. Proportion and extent of manifestation of molar-incisorhypomineralizations according to different phenotypes. J Public Health Dent 2014; 74: 42-49. 
10. Pitts N B, Chestnutt I G, Evans D, White D, Chadwick $B$, Steele J G. The dentinal caries experience of children in the United Kingdom, 2003. Br Dent J 2006: 200: 313-320.

11. Albadri S, Zaitoun H, McDonnell S T, Davidson LE. Extraction of first permanent molar teeth: results from three dental hospitals. Br Dent J 2007; 203: E14, discussion 408-409.

12. Holm U. Problems of compensative extraction in cases with loss of permanent molars. Rep Congr Eur Orthod Soc 1970: 409-427.

13. Jalevik B, Moller M. Evaluation of spontaneous space closure and development of permanent dentition after extraction of hypomineralized permanent first molars. Int J Paediatr Dent 2007; 17: 328-335.

14. Mejare I, Bergman E, Grindefjord M.

Hypomineralized molars and incisors of unknown origin: treatment outcome at age 18 years. Int J Paediatr Dent 2005; 15: 20-28.

15. Innes N, Borrie F, Bearn D et al. Should I eXtract Every Six dental trial (SIXES): study protocol for a randomized controlled trial. Trials 2013; 14: 59.

16. Ong D C, Bleakley J E. Compromised first permanent molars: an orthodontic perspective. Aust Dent $J$ 2010; 55: 2-14

17. Williams J K, Gowans A J. Hypomineralised first permanent molars and the orthodontist. Eur J Paediatr Dent 2003; 4: 129-132.

18. Caglaroglu M, Kilic N, Erdem A. Effects of early unilateral first molar extraction on skeletal asymmetry. Am J Orthod Dentofacial Orthop 2008; 134: 270-275.
19. Telli A E, Aytan S. [Changes in the dental arch due to obligatory early extraction of first permanent molars]. Turk Ortodonti Derg 1989; 2: 138-143.

20. Plint D A. The effect on the occlusion of the loss of one or more first permanent molars. Rep Congr Eur Orthod Soc 1970: 329-336.

21. Teo T K, Ashley P F, Parekh S, Noar J. The evaluation of spontaneous space closure after the extraction of first permanent molars. Eur Arch Paediatr Dent 2013; 14: 207-212.

22. Thilander $B$, Jakobsson S O, Skagius S. Orthodontic sequelae of extraction of permanent first molars. Skand Dent J 1963; 71: 380.

23. Thilander B, Skagius S. Orthodontic sequelae of extraction of permanent first molars. A longitudinal study. Rep Congr Eur Orthod Soc 1970: 429-442.

24. Thunold K. Early loss of the first molars 25 years after. Rep Congr Eur Orthod Soc 1970: 349-365.

25. Hallett G E M, Burke PH. Symmetrical extraction of first permanent molars. Factors controlling results in the lower arch. Trans Eur Orthod Soc 1961: 238-253.

26. Abu Aihaija E S, McSheny P F, Richardson A. A cephalometric study of the effect of extraction of lower first permanent molars. J Clin Paediatr Dent 2000; 24: 195-198.

27. Richardson A. Spontaneous changes in the incisor relationship following extraction of lower first permanent molars. Br J Orthod 1979; 6: 85-90.

28. Normando A D, Maia F A, Ursi W J, Simone J L. Dentoalveolar changes after unilateral extractions of mandibular first molars and their influence on third molar development and position. World J Orthod 2010; 11: 55-60.

29. Halicioglu K, Toptas O, Akkas I, Celikoglu M. Permanent first molar extraction in adolescents and young adults and its effect on the development of third molar. Clin Oral Investig 2014; 18: 1489-1494.

30. Williams R, Hosila F J. The effect of different extraction sites upon incisor retraction. Am J Orthod 1976 69: 388-410.

31. Yavuz I, Baydas B, Ikbal A, Dagsuyu I M, Ceylan I. Effects of early loss of permanent first molars on the development of third molars. Am J Orthod Dentofacial Orthop 2006; 130: 634-638.

32. Ay $\mathrm{S}$, Agar U, Bicakci A A, Kosger H H. Changes in mandibular third molar angle and position after unilateral mandibular first molar extraction. Am J Orthod Dentofacial Orthop 2006; 129: 36-41.

33. Jacobs C, Jacobs-Muller C, Luley C, Erbe C, Wehrbein $\mathrm{H}$. Orthodontic space closure after first molar extraction without skeletal anchorage. J Orofac Orthop 2011; 72: 51-60.

34. Sandler P J, Atkinson R, Murray A M. For four sixes. Am J Orthod Dentofacial Orthop 2000; 117: 418-434.

35. Gill D S, Lee R T, Tredwin C J. Treatment planning for the loss of first permanent molars. Dent Update 2001; 28: 304-308.

36. Mackie I C, Blinkhorn A S, Davies P H J. The extraction of permanent molars during the mixed dentition period - a guide to treatment planning. J Paed Dent 1989; 5: 85-92. 